\title{
PARENTAL SELF-EFFICACY DAN PRAKTIK PENGASUHAN MENENTUKAN PERILAKU AGRESIF ANAK USIA PRASEKOLAH
}

\author{
An Nisaa Noor Rachmawati ${ }^{1 *}$, Dwi Hastuti ${ }^{1}$ \\ ${ }^{1}$ Departemen Ilmu Keluarga dan Konsumen, Fakultas Ekologi Manusia, Institut Pertanian Bogor, \\ Bogor, 16680, Indonesia
}

*)Email: annisanoor13@gmail.com

\begin{abstract}
Abstrak
Penelitian ini bertujuan untuk menganalisis faktor-faktor yang memengaruhi perilaku agresif pada anak usia prasekolah. Penelitian ini melibatkan 36 keluarga dengan anak usia prasekolah yang dipilih secara purposive. Kriteria contoh pada penelitian ini adalah ibu sebagai pengasuh utama dan memiliki anak bersekolah di dua lembaga PAUD yang berlokasi di Desa Ciasmara, Kecamatan Pamijahan, Kabupaten Bogor. Data dikumpulkan dengan teknik wawancara menggunakan kuesioner. Data dianalisis menggunakan uji regresi linear berganda. Hasil penelitian menunjukkan bahwa menunjukkan bahwa lebih dari separuh ibu memiliki parental self-efficacy di atas rata-rata. Hal ini berarti lebih dari separuh ibu pada penelitian ini memiliki keyakinan yang tinggi akan kemampuannya dalam mengasuh anak. Praktik pengasuhan pada dimensi pendisiplinan yang dilakukan ibu terlihat dalam bentuk pemberian hukuman berupa pengambilan kesenangan anak seperti tidak boleh bermain, menonton TV, atau jajan. Sementara itu, praktik pengasuhan negatif ditunjukkan dengan orang tua lebih sering mengancam menghukum anak untuk menghentikan perilaku anak yang tidak baik. Hasil penelitian menemukan bahwa hampir dua pertiga anak berperilaku agresif di bawah rata-rata. Hasil penelitian ini menemukan pengaruh antara parental self-efficacy dan praktik pengasuhan negatif terhadap perilaku agresif anak usia prasekolah.
\end{abstract}

Kata kunci: anak usia prasekolah, parental self-efficacy, perilaku agresif, praktik pengasuhan

\section{Parental Self-Efficacy and Parenting Practice to Aggressive Behavior in Preschool Children}

\begin{abstract}
This study aimed to analyze the factors which influence aggressive behavior. This study involved 36 families with preschool children, which were chosen purposively. The sample criteria of this study were mothers as primary caregiver who have children that was become students in early childhood care in Ciasmara Village, Pamijahan Sub District, Bogor District. The data were collected by interview technique using questionnaire. Data were analyzed by multiple linear regression test. The results showed that more than half of mothers had above average parental self-efficacy. This means that more than half of mothers in this study have high confidence in their ability to care for children. Parenting practice, especially in discipline parental dimension of mothers, was in the form of giving punishment like prohibit children to do what she/he likes such as prohibit to play, to watch TV or to buy snack. Moreover, negative parenting practices were shown in the form of not threatening to punish a child for stopping child's bad behavior. The result also showed that almost two-thirds of children behave aggressively below average. The results of this study found an influence of parental self-efficacy and negative parenting practices on aggressive behavior of preschool children.
\end{abstract}

Keyword: aggressive behavior, parental self-efficacy, parenting practice, preschool children

\section{PENDAHULUAN}

Anak usia prasekolah adalah anak yang berada pada rentang usia 3-6 tahun (Santrock, 2011). Pada masa anak usia prasekolah, kemampuan bersosialisasi, persiapan untuk masuk sekolah, dan perluasan pertemanan merupakan hal-hal yang paling penting (Evans \& Myers, 2000). Menurut Santrock (2011) anak usia prasekolah sedang berada pada tahapan initiative versus guilty, yaitu tahapan anak akan mulai yakin pada dirinya sendiri dan menemukan pribadi yang diinginkan. Pada tahapan ini anak usia prasekolah banyak mengidentifikasi dan meniru orang tuanya sehingga kesalahan pada praktik pengasuhan akan meningkatkan jumlah anak yang memiliki masalah dalam berperilaku. Albert Bandura menjelaskan anak laki-laki yang ayahnya berperilaku agresif akan memperlihatkan perilaku yang agresif juga (Santrock, 2011). Hal tersebut terjadi karena anak belajar meniru 
suatu perilaku tertentu dari lingkungannya (Hastuti, 2015).

Praktik pengasuhan dibagi menjadi dua, yaitu praktik pengasuhan konstruktif dan destruktif (Simons et al., 1990). Pada penelitian ini peneliti menggunakan istilah praktik pengasuhan positif dan negatif untuk menggambarkan praktik pengasuhan yang konstruktif dan destruktif. Praktik pengasuhan konstruktif akan menghasilkan perkembangan anak yang positif, sedangkan praktik pengasuhan destruktif akan menghasilkan perkembangan anak yang negatif. Kecenderungan orang tua menerapkan salah satu praktik pengasuhan dipengaruhi oleh beberapa faktor seperti kondisi sosial ekonomi keluarga, karakteristik orang tua termasuk riwayat pengasuhan orang tua, adanya tantangan dan tidak adanya dukungan untuk menjadi orang tua, serta kurangnya kesepakatan menjadi orang tua (Hastuti, 2015). Selain faktor-faktor yang telah disebutkan praktik pengasuhan juga dipengaruhi oleh parental self-efficacy yang dimiliki oleh orang tua.

Parental self-efficacy merupakan pengembangan dari teori self-efficacy Bandura mengenai keyakinan yang dimiliki seseorang akan kemampuannya pada bidang tertentu. Parental self-efficacy dikembangkan oleh Pompa (1990;1991), diacu dalam Duane dan Grusec (2006) yang memasukkan unsur selfefficacy ke dalam praktik pengasuhan. Parental self-efficacy adalah keyakinan yang dimiliki orang tua terkait kemampuannya dalam mengasuh anak (Coleman \& Karraker, 2003). Parental self-efficacy terkait dengan pola asuh yang lebih efektif dan anak yang dihasilkan akan lebih baik (Dowling, 2014). Parental selfefficacy berhubungan dengan peningkatan sensitivitas, kehangatan, dan responsif orang tua terhadap anaknya (Dumka et al., 2010). Menurunnya parental self-efficacy dikaitkan dengan ketidakberfungsian pengasuhan yang tinggi, termasuk kelalaian dan reaktivitas yang berlebihan (Sanders \& Woolley, 2005), tingkat depresi ibu yang lebih tinggi dan tingkat kepuasan orang tua yang lebih rendah (Dowling, 2014). Menurut Dowling (2014) parental self-efficacy harus menjadi pertimbangan penting untuk meningkatkan kompetensi orang tua dan mekanisme yang mendasari interaksi antara parental selfefficacy dan pengasuhan anak yang tidak jelas. Parental self-efficacy yang tinggi terkait dengan pola asuh strategi dan perilaku yang positif (Coleman \& Karraker, 1998). Saat orang tua merasa kompeten dengan kemampuannya, cenderung menggunakan praktik pengasuhan yang lebih efektif, yang akan mendorong hasil perkembangan positif (Dowling, 2014). Parental self-efficacy ditemukan sebagai mediator antara pengalaman ibu dengan anak-anak, pendidikan, dan kepuasan dengan mengasuh anak (Coleman \& Karraker, 2000) kepercayaan yang dipegang orang tua, kemampuan untuk mengatur dan melaksanakan serangkaian tugas yang berhubungan dengan mengasuh anak (LeahyWarren, McCarthy, \& Corcoran, 2011). Parental self-efficacy juga menjadi faktor pelindung terhadap permasalahan anak dan remaja (Jones et al., 2008; Page et al., 2010), sehingga penting orang tua memiliki keyakinan tersebut.

Agresi merupakan perilaku yang dimaksudkan untuk melukai orang lain yang menghindar agar tidak terluka (Anderson \& Bushman, 2001). Menurut Papalia dan Olds (1986), agresivitas pada anak prasekolah dapat berlanjut jika anak dapat memperoleh keinginannya melalui perilaku agresif tersebut. Pada umumnya agresi yang dilakukan anak prasekolah bertujuan untuk mempertahankan mainan maupun wilayahnya. Perilaku agresif pada anak usia prasekolah biasanya ditunjukkan ketika anak bermain dengan temannya. Perilaku agresif merupakan perilaku yang secara alami berkembang pada diri anak selama masa pematangan (Caplan, 1978). Menurut Imtaz, Yasi, dan Yaseen (2010) menyatakan semakin muda usia seseorang cenderung semakin agresif dan seiring bertambahnya usia maka agresi akan berkurang. Namun demikian, orang tua tidak boleh membiarkan perilaku tersebut terus berkembang pada diri anak. Anak harus mengetahui bahwa setiap orang memiliki hak yang harus dihargai dan anak tidak boleh menyakiti orang lain. Menurut Papalia dan Olds (1986) semakin sering anak mendapatkan sesuatu melalui perilaku agresif semakin besar potensi anak menjadi lebih agresif. Agresi juga akan merusak kehidupan sosial karena individu yang agresif tidak dapat menguraikan situasi sehingga melakukan kekerasan atau terisolasi (Calvete \& Orue, 2010). Orang tua diharapkan dapat menghentikan perilaku agresif sejak dini pada anak prasekolah sehingga tidak berkembang menjadi perilaku-perilaku kenakalan lainnya di masa yang akan datang seperti bullying dan masalah kriminal ketika remaja. Menurut Arriani (2014) salah satu penyebab munculnya perilaku agresif pada anak adalah pendisiplinan orang tua dengan kekerasan, 
anak yang memiliki perilaku agresif terbiasa melihat dan menerima hukuman fisik dari orang tua atau lingkungan terdekatnya.

Penelitian longitudinal yang dilakukan oleh Stromshak et al., (2000) pada anak usia prasekolah menunjukkan bahwa metode pendisiplinan yang melibatkan hukuman fisik berhubungan dengan internalisasi perilaku agresif pada anak. Praktik pengasuhan yang melibatkan agresi fisik berhubungan dengan perilaku agresif pada anak. Hasil penelitian ini diperkuat oleh hasil penelitian Dumka et al., (2010) yang menemukan cara untuk mencegah perilaku agresif pada anak melalui praktik pengasuhan yang hangat dan terlibat lebih efektif dibandingkan dengan praktik pengasuhan yang bersifat terlalu mengontrol anak. Garcia dan Alampay (2012) memaparkan hasil penelitiannya yang menunjukkan bahwa parental efficacy merupakan sumberdaya yang penting bagi ayah yang dapat mengurangi efek tekanan dalam pengasuhan. Ayah yang memiliki tekanan akan memengaruhi pengasuhannya dan parental self-efficacy akan mengurangi cara pendisiplinan yang agresi dan kasar. Hasil penelitian Dumka et al., (2010) juga menunjukkan bahwa ibu yang memiliki parental self-efficacy yang tinggi menunjukkan praktik pengasuhan yang akan mengurangi perilaku yang bermasalah. Hal tersebut membuktikan bahwa parental self-efficacy memengaruhi perilaku agresif anak melalui praktik pengasuhan yang diterapkan.

Berdasarkan hasil monitoring tahun 2012 yang dilakukan KPAI disembilan provinsi di Indonesia menunjukkan sebanyak 91 persen anak menjadi korban kekerasan di lingkungan keluarga (KPAI, 2015). Selain itu, laporan terbaru KPAl (2016) menunjukkan terdapat 22.109 kasus kekerasan pada anak yang terjadi di Indonesia selama tahun 2011-2016 dan sebanyak 4.294 kasus kekerasan yang menimpa anak terjadi di dalam lingkungan keluarga. Salah satu contoh kekerasan pada anak yang terjadi di dalam lingkungan keluarga berhubungan dengan praktik pengasuhan yang bermasalah. Data KPAI 2011-2015 menunjukkan terdapat 3.160 kasus kekerasan pada anak yang berhubungan dengan pengasuhan (KPAI, 2015). Beberapa penelitian yang telah dilakukan (Caplan, 1978; Papalia \& Olds, 1986; Reebye, 2005; Erlanti et al., 2016), faktor yang memengaruhi perilaku agresif pada anak prasekolah adalah karakteristik anak, karakteristik keluarga, lingkungan sekitar, faktor biologis, dan praktik pengasuhan yang diterapkan oleh orang tua. Namun, dari seluruh faktor pemicu terbentuknya perilaku agresif pada anak, praktik pengasuhanlah yang paling banyak diungkapkan dalam berbagai penelitian. Contohnya adalah hasil penelitian Stromshaket al., (2000) yang menemukan terdapat hubungan positif antara perilaku anak yang agresif dengan praktik pengasuhan yang melibatakan agresi secara fisik.Artinya anak yang memiliki pengalaman pendisiplinan melalui hukuman, penamparan, dan agresi fisik menunjukkan peningkatan pola perilaku bermasalah. Praktik pengasuhan yang diterapkan orang tua dipengaruhi oleh tingkat parental self-efficacy yang dimiliki oleh orang tua. Pada penelitian ini, peneliti tertarik untuk meneliti parental self-efficacy yang dimiliki oleh orang tua. Berdasarkan pemaranan diatas, tujuan penelitian ini adalah; (1) mengidentifikasi karakteristik anak, karakteristik keluarga, parental self-efficacy, praktik pengasuhan, dan perilaku agresif; (2) mengetahui faktor-faktor yang memengaruhi perilaku agresif anak.

\section{METODE}

Penelitian ini merupakan bagian dari penelitian payung Hibah Kompetensi (Hikom) Pendidikan Tinggi yang dilaksanakan oleh Hastuti dan Alfiasari tahun 2017. Penelitian ini menggunakan desain cross-sectional study. Penelitian ini dilaksanakan di Desa Ciasmara, Kecamatan Pamijahan, Kabupaten Bogor. Lokasi ini dipilih secara purposive berdasarkan salah satu kriteria penelitian HIKOM, yaitu daerah yang memiliki pertanian yang luas. Waktu penelitian mencakup pengumpulan data, pengolahan, dan penulisan laporan dilakukan pada bulan April 2017 hingga Mei 2017.

Populasi penelitian ini adalah seluruh keluarga yang memiliki anak prasekolah yang bertempat tinggal di Desa Ciasmara, Kecamatan Pamijahan, Kabupaten Bogor. Contoh dari penelitian ini adalah keluarga yang memiliki anak usia prasekolah bersekolah di PAUD Mawar dan Nurul Fajriah serta ibu sebagai pengasuh utama. Jumlah contoh yang diambil adalah 16 ibu yang memiliki anak bersekolah di PAUD Mawar dan 20 ibu yang memiliki anak bersekolah di Nurul Fajriah, sehingga keseluruhan contoh berjumlah 36 ibu.

Jenis data yang dikumpulkan dalam penelitian ini merupakan data primer. Data primer dikumpulkan dengan cara wawancara menggunakan instrumen yang pengisiannya dilakukan oleh enumerator. Data primer meliputi; (1) Karakteristik keluarga, 
Karakteristik anak, (3) Parental self-efficacy, (4) Praktik pengasuhan, (5) Perilaku agresif anak. Karakteristik keluarga terdiri atas usia, lama pendidikan, jenis pekerjaan, pendapatan per kapita, dan besar keluarga. Berdasarkan Papalia et al., (2009) usia ayah dan ibu dibagi menjadi tiga kategori yaitu dewasa awal (18-40 tahun), dewasa madya (41-60 tahun), dan dewasa tua ( $>60$ tahun). Pendidikan orang tua dilihat dari lama pendidikan dengan empat kategori yakni (1) 0-6 tahun, (2) 6-8 tahun, (3) 9-11 tahun, (4) $\geq 12$ tahun. Jenis pekerjaan orang tua diukur berdasarkan pekerjaan utama yang dilakukan orang tua untuk menghidupi keluarga, yaitu (1) tidak bekerja, (2) petani, (3) bukan petani. Pendapatan keluarga yang diukur adalah pendapatan keluarga per kapita per bulan, kemudian dibandingkan dengan garis kemiskinan Kabupaten Bogor tahun (2015) yaitu Rp290.874,00 per kapita per bulan (BPS 2016). Selanjutnya, keluarga dikategorikan miskin jika memiliki pendapatan keluarga kurang dari Rp290.874,00 dan keluarga dikatakan tidak miskin jika memiliki pendapatan keluarga lebih dari sama dengan Rp290.874,00. Berdasarkan jumlah anggota keluarga, besar keluarga dibagi menjadi tiga kategori yaitu keluarga kecil (2-4 orang), sedang (5-7 orang) dan keluarga besar $(\geq 8$ orang). Karakteristik anak terdiri atas usia dan jenis kelamin. Usia anak dibedakan menjadi tiga kategori yaitu 48-60 bulan, 61-72 bulan, dan 73-84 bulan. Jenis kelamin dibedakan menjadi dua kategori yaitu (0) laki-laki dan (1) perempuan.

Parental self-efficacy diukur dengan mengadopsi alat ukur Centre of research in Primary and Community Care University of Hertforshide yaitu Tool to measure Parental Self-efficacy (TOPSE) Instrumen TOPSE terdiri dari enam dimensi yang meliputi dimensi emosi dan kasih sayang, bermain dan kesenangan, empati dan pengertian, kontrol, serta disiplin dan penerapan aturan. Jumlah pertanyaan pada instrumen ini sebanyak 30 pertanyaan dengan skala Likert 0 (tidak sesuai) hingga 2 (sesuai) dan memiliki nilai Cronbach's alpha 0,833. Pengasuhan diukur dengan alat ukur Webster Stratton, Reid and Hammond (2001) yaitu Parent Practices Interview (PPI) yang telah dimodifikasi oleh peneliti untuk keperluan penelitian dengan Praktik pengasuhan positif memiliki jumlah pertanyaan sebanyak 22 butir dan memiliki nilai Cronbach's alpha 0,763. Sementara itu, praktik pengasuhan negatif meliputi tiga dimensi yaitu pendisiplinan dengan kekerasan, pendisiplinan yang tidak konsisten, serta menunjukkan kemarahan. Praktik pengasuhan negatif memiliki jumlah pertanyaan sebanyak 12 butir pernyataan dan memiliki nilai Cronbach's alpha 0,900. Perilaku agresif diukur dengan alat ukur Thomas M Achenbach (1991) yaitu Child Behavior Check List (CBCL) yang telah dimodifikasi oleh peneliti untuk keperluan penelitian dengan Instrumen ini menggunakan skala Likert 0 (tidak benar) hingga 2 (sangat benar atau sering benar) dan memiliki nilai Cronbach's alpha 0,892.

Penilaian variabel penelitian dilakukan dengan sistem skoring yang dibuat secara konsisten, yaitu semakin tinggi skor semakin tinggi pula kategorinya. Skor/nilai variabel-variabel yang diteliti dikategorikan dengan menggunakan cut-off point skor indeks berdasarkan nilai ratarata. Kategori di bawah rata-rata jika skor indeks lebih kecil dari nilai rata-rata dan kategori di atas rata-rata jika skor indeks lebih besar sama dengan nilai rata-rata. Kuesioner terdiri atas beberapa pertanyaan tertutup lalu jawaban dari responden diolah dan dikelompokkan oleh peneliti. Selanjutnya data dianalisis dengan analisis deksriptif dan inferensia. Analisis inferensia yang digunakan adalah regresi linear berganda metode backward, sehingga variabel yang tidak memiliki pengaruh secara signifikan seperti tidak akan masuk ke dalam model regresi.

\section{HASIL}

\section{Karakteristik Anak dan Keluarga}

Hampir dua pertiga keluarga $(61,1 \%)$ memiliki anak perempuan yang berusia 61-72 bulan dengan rata-rata usia 67,83 bulan. Lebih dari separuh usia ayah dan ibu berada pada rentang usia 18 sampai 40 tahun (dewasa awal). Rata-rata usia ibu (31,97 tahun) lebih muda jika dibandingkan dengan rata-rata usia ayah (37,11 tahun). Sebanyak 47,2 persen ayah memiliki tingkat pendidikan akhir yang setara dengan sekolah dasar (SD). Rata-rata lama pendidikan ayah adalah 7,94 tahun. Sementara itu, 52,8 persen ibu memiliki tingkat pendidikan akhir setara dengan sekolah dasar dengan rata-rata 7,64 tahun. Lebih dari tiga perempat ayah bekerja sebagai bukan petani. Sebanyak 41,7 persen ayah bermata pencaharian sebagai pedagang, sedangkan lebih dari separuh ibu tidak bekerja (IRT). Hampit tiga perempat keluarga $(72,2 \%)$ berada dalam kategori tidak miskin dan memiliki pendapatan perkapita lebih besar dari garis kemiskinan Kabupaten Bogor Rp290.874,00 (BPS 2016). Separuh keluarga berada dalam kategori keluarga sedang dengan jumlah anggota rata-rata 5 orang (Tabel 1). 
Tabel 1 Nilai minimum, maksimum, dan ratarata karakteristik anak serta karakteristik kelurga

\begin{tabular}{|c|c|c|c|}
\hline Variabel & Min & Maks & $\begin{array}{c}\text { Rata-rata } \pm \\
\text { SD }\end{array}$ \\
\hline $\begin{array}{l}\text { Usia anak } \\
\text { (bulan) }\end{array}$ & 49 & 84 & $67,83 \pm 9,74$ \\
\hline $\begin{array}{l}\text { Usia ayah } \\
\text { (tahun) }\end{array}$ & 29 & 65 & $\begin{array}{c}37,11 \pm \\
8,54\end{array}$ \\
\hline $\begin{array}{l}\text { Usia } \\
\text { (tahun) }\end{array}$ & 21 & 49 & $\begin{array}{c}31,97 \pm \\
6,06\end{array}$ \\
\hline $\begin{array}{l}\text { Lama } \\
\text { pendidikan } \\
\text { ayah (tahun) }\end{array}$ & 3 & 12 & $7,94 \pm 2,51$ \\
\hline $\begin{array}{l}\text { Lama } \\
\text { pendidikan } \\
\text { ibu (tahun) }\end{array}$ & 3 & 12 & $7,64 \pm 2,61$ \\
\hline $\begin{array}{l}\text { Besar } \\
\text { keluarga } \\
\text { (orang) }\end{array}$ & 3 & 7 & $5 \pm 1,17$ \\
\hline $\begin{array}{l}\text { Pendapatan } \\
\text { perkapita } \\
\text { (rupiah) }\end{array}$ & $50.000,00$ & $1.666,67$ & $\begin{array}{c}480.830,72 \\
\pm \\
307.682,32\end{array}$ \\
\hline
\end{tabular}

\section{Parental Self-Efficacy}

Berdasarkan hasil penelitian yang dtunjukkan pada Tabel 2, diketahui bahwa lebih dari separuh ibu $(55,6 \%)$ memiliki parental selfefficacy di atas rata-rata. Rata-rata indeks parental self-efficacy sebesar 75,14 , dengan nilai indeks terendah sebesar 42 dan nilai indeks tertinggi sebesar 98 . Hal ini berarti lebih dari separuh ibu pada penelitian ini memiliki keyakinan yang tinggi akan kemampuannya dalam mengasuh anak. Hasil penelitian juga menunjukkan bahwa dimensi emosi dan kasih sayang memiliki nilai rata-rata indeks sebesar 88,03 . Tingginya dimensi emosi dan kasih sayang ditunjukkan ibu merasa mampu untuk memberikan kasih sayang kepada anak seperti mengucapkan sayang, memeluk, dan mencium anak. Dimensi bermain dan kesenangan memiliki nilai rata-rata indeks 81,42, sedangkan dimensi empati dan pengertian memiliki nilai rata-rata indeks 79,61 .

Hasil analisis juga menemukan bahwa parental self-efficacy dimensi kontrol memiliki rata-rata indeks 62,92, sedangkan dimensi disiplin dan penerapan aturan memiliki rata-rata indeks 63,56. Berdasarkan hasil penelitian dapat disimpulkan bahwa rata-rata contoh belum memiliki kemampuan untuk mengontrol dirinya serta anaknya. Sama hal nya dengan kemampuan untuk disiplin dan penerapan aturan yang dimiliki oleh contoh, hasil penelitian menemukan bahwa masih belum baik dalam pelaksanannya atau belum konsisten.
Tabel 2 Sebaran contoh berdasarkan parental self-efficacy dan analisis deskriptif

\begin{tabular}{|c|c|c|}
\hline Parental self-efficacy & $\mathrm{n}$ & $\%$ \\
\hline $\begin{array}{l}\text { Dibawah rata-rata } \\
(00,00-75,14)\end{array}$ & 16 & 44,4 \\
\hline $\begin{array}{l}\text { Diatas rata-rata } \\
(75,14-100,00)\end{array}$ & 20 & 55,6 \\
\hline Total & 36 & 100 \\
\hline Min-Maks (indeks) & \multicolumn{2}{|c|}{$42,00-98,00$} \\
\hline Rata-rata $\pm S D$ (indeks) & \multicolumn{2}{|c|}{$75,14 \pm 13,560$} \\
\hline
\end{tabular}

\section{Praktik Pengasuhan}

Tabel 3 menunjukkan bahwa dimensi praktik pengasuhan positif yang memiliki nilai rata-rata tertinggi yaitu sebesar 75,46 adalah dimensi komunikasi positif. Sementara itu, dimensi praktik pengasuhan positif yang memiliki nilai rata-rata terendah sebesar 27,78 adalah dimensi pendisiplinan yang tepat. Pendisiplinan yang tepat meliputi pemberian hukuman berupa pengambilan kesenangan anak seperti tidak boleh bermain, menonton TV, atau jajan. Selain itu, pendisiplinan yang tepat juga dapat berupa menghukum anak bukan hanya sekedar mengancam dan menghukum anak jika anak bersalah. Dimensi praktik pengasuhan negatif yang memiliki ratarata tertinggi adalah dimensi pendisiplinan tidak konsisten dengan nilai rata-rata sebesar 57,41 . Orang tua pada umumnya lebih sering mengancam menghukum anak untuk menghentikan perilaku anak yang tidak baik. Hal ini berarti lebih dari separuh ibu tidak mendisiplinkan anaknya dengan cara yang tepat karena lebih sering mengancam anak. Sementara itu, hasil analisis menemukan bahwa dimensi pendisiplinan dengan kekerasan memiliki nilai rata-rata terendah sebesar 41,67. Rendahnya rata-rata indeks dimensi pendisiplinan dengan kekerasan dikarenakan ibu lebih suka mengancam anak. Dapat disimpulkan bahwa ibu tidak menerapkan pendisiplinan yang tepat dan cenderung menggunakan pendisiplinan yang tidak konsisten.

Tabel 3 Rata-rata indeks dimensi praktik pengasuhan positif

\begin{tabular}{lc}
\hline \multicolumn{1}{c}{ Dimensi Praktik Pengasuhan } & $\begin{array}{c}\text { Rata- rata } \\
\text { indeks }\end{array}$ \\
\hline Praktik Pengasuhan Positif & $\mathbf{5 2 , 3 1}$ \\
Pemberian pujian & 50,88 \\
Pendisiplinan yang tepat & 27,78 \\
Komunikasi positif & 75,46 \\
Praktik Pengasuhan Negatif & $\mathbf{4 8 , 8 1}$ \\
Menunjukkan kemarahan & 47,02 \\
Pendisiplinan dengan kekerasan & 41,67 \\
Pendisiplinan yang tidak & 57,41 \\
konsisten & \\
\hline
\end{tabular}


Tabel 4 Sebaran anak berdasarkan perilaku agresif dan analisis deskriptif

\begin{tabular}{lcc}
\hline \multicolumn{1}{c}{ Perilaku Agresif } & $\mathrm{n}$ & $\%$ \\
\hline Dibawah rata-rata $(<36,30)$ & 22 & 61,1 \\
Diatas rata-rata $(\geq 36,30)$ & 14 & 38,9 \\
\hline Total & 36 & 100 \\
\hline Min-Maks (indeks) & $2,00-82,00$ \\
Rata-rata $\pm S t d e v$ (indeks) & $36,30 \pm 20,82$ \\
\hline
\end{tabular}

\section{Perilaku Agresif}

Tabel 4 menunjukkan bahwa hampir dua pertiga anak $(61,1 \%)$ berperilaku agresif di bawah rata-rata $(<36,30)$. Perilaku agresif terdiri dari empat dimensi yang meliputi; 1) agresi fisik; 2) agresi verbal; 3) pemarah; dan 4) permusuhan. Hasil penelitian menunjukkan bahwa perilaku agresif tertinggi berada pada dimensi pemarah dengan nilai rata-rata indeks secara berurutan sebesar 49,44 , ditunjukkan dengan sebanyak 55,6 persen anak sering merasa cemburu. Dimensi agresi verbal memiliki nilai tertinggi kedua, ditunjukkan sebanyak 27,8 persen anak sering berkatakata kasar. Kata-kata kasar yang sering diucapkan anak kepada teman dan saudaranya adalah nama-nama hewan. Sementara itu, dimensi agresi fisik memiliki nilai terendah sebesar 25,11. Agresi verbal dan fisik yang dilakukan anak sering ditujukan kepada teman dan saudaranya

\section{Faktor-faktor yang Memengaruhi Perilaku Agresif}

Peneliti menggunakan metode backward dalam pengujian regresi linear berganda, sehingga variabel yang tidak memiliki pengaruh secara signifikan seperti karakteristik keluarga tidak akan masuk ke dalam model regresi. Penggunaan metode backward bertujuan untuk mendapatkan model yang terbaik dan mengeluarkan variabel-variabel yang tidak memengaruhi perilaku agresif.
Berdasarkan hasil uji regresi linear berganda terlihat bahwa parental self-efficacy dan praktik pengasuhan yang negatif berpengaruh signifikan terhadap perilaku agresif $(p<0,05)$. Parental self-efficacy berpengaruh negatif signifikan terhadap perilaku agresif anak $(B=-$ 0,686). Hal tersebut berarti bahwa, setiap kenaikan satu poin parental self-efficacy akan menurunkan perilaku agresif anak sebesar 0,686 poin. Praktik pengasuhan yang negatif memiliki pengaruh positif yang signifikan terhadap perilaku agresif anak $(B=0,340)$. Artinya, praktik pengasuhan negatif yang tinggi akan menaikkan perilaku agresif anak sebesar 0,340 poin. Nilai Adjusted $R$ Square sebesar 0,532 memiliki arti bahwa 53,2 persen perilaku agresif dipengaruhi oleh variabel bebas yang diteliti, sedangkan sisanya 46,8 persen dipengaruhi oleh variabel lain yang tidak diteliti. Nilai $F$ hitung lebih besar dibandingkan nilai $F$ tabel $(8,961>2,67)$ sehingga dapat disimpulkan bahwa seluruh variabel independen memengaruhi variabel dependen yang ada di model.

\section{PEMBAHASAN}

Setiap anak dilahirkan dan dibesarkan dalam sebuah lembaga yang disebut keluarga. Tumbuh kembang seorang anak ditentukan oleh kondisi lingkungan tempat anak dibesarkan. Lingkungan yang ideal untuk anak adalah lingkungan yang penuh dengan cinta, kasih sayang, serta kehangatan. Anak yang dibesarkan pada lingkungan yang penuh dengan konflik dan stres yang dimiliki oleh orang tua dapat mengahasilkan anak yang memiliki emosi negatif yang secara tidak langsung ditiru dari orang tuanya. Berdasarkan teori sistem, suatu sistem terdiri dari beberapa unsur yang saling berhubungan dan saling memengaruhi (Hastuti, 2015). Bronfrenbrenner dalam teori ekologi membagi lingkungan menjadi empat yaitu lingkungan mikrosistem, mesosistem, eksosistem, dan makrosistem.

Tabel 5 Koefisien regresi jenis kelamin anak, usia anak, parental self-efficacy, dan praktik pengasuhan negatif.

\begin{tabular}{|c|c|c|c|}
\hline Variabel & $\begin{array}{c}\text { B } \\
\text { (Tidak Terstandardisasi) }\end{array}$ & $\begin{array}{c}\beta \\
\text { (terstandardisasi) }\end{array}$ & Sig. \\
\hline (Constant) & 48,111 & & 0,093 \\
\hline $\begin{array}{l}\text { Jenis kelamin anak ( } 0=\text { Laki-laki, } 1= \\
\text { perempuan) }\end{array}$ & $-8,188$ & $-0,194$ & 0,112 \\
\hline Usia anak (bulan) & 0,291 & 0,136 & 0,258 \\
\hline Parental self-efficacy (skor indeks) & $-0,686$ & $-0,447$ & $0,002^{* *}$ \\
\hline Praktik pengasuhan negatif (skor indeks) & 0,340 & 0,377 & $0,007^{* *}$ \\
\hline $\mathrm{F}$ & & 8,961 & \\
\hline Adj R Square & & 0,532 & \\
\hline P-value. & & $0,000^{* *}$ & \\
\hline
\end{tabular}


Keluarga merupakan salah satu lingkungan mikrosistem tempat anak pertama kali berinteraksi. Keluarga berinteraksi dan memengaruhi anak secara langsung begitu pula sebaliknya, sehingga yang dilakukan oleh orang tua dapat memengaruhi anak begitu pula dengan lingkungan yang dapat memengaruhi anak. Masa usia prasekolah merupakan masa yang rentan dan penting dalam proses pertumbuhan dan perkembangan. Hal yang terjadi pada masa ini, akan memengaruhi kualitas anak di masa depan. Pada masa prasekolah anak banyak belajar dari lingkungannya yang kemudian akan membentuk dirinya dimasa yang akan datang. Menurut Bandura dalam teori pembelajaran sosial, seseorang dapat belajar dengan mengamati atau melihat tingkah laku orang lain yang disebut sebagai model (Hastuti, 2015).

Parental self-efficacy merupakan salah satu komponen yang penting dalam pengasuhan. Hal ini dikarenakan self-efficacy adalah atributif dan sikap yang dimiliki oleh orang tua terutama ibu sehingga dapat mengarahkan pengasuhan (Rudy \& Grusec, 2006). Hasil penelitian menunjukkan bahwa lebih dari separuh ibu berada dalam kategori ibu yang memiliki parental self-efficacy di atas rata-rata. Hal tersebut dikarenakan sebagian besar ibu merasa mereka harus yakin akan kemampuannya dalam pengasuhan. Tingginya parental self-efficacy yang dimiliki oleh ibu dipengaruhi oleh berbagai faktor. Faktor-faktor tersebut adalah usia, lama pendidikan, status bekerja, depresi yang dialami ibu, dan pendapatan keluarga (Froman \& Owen 1990; Weaver et al. 2003; Salonen 2010; Kassabri et al. 2014; Azmoude et al., 2015). Tingginya parental self-efficacy yang dimiliki oleh ibu akan mendorong ibu menerapkan praktik pengasuhan yang positif begitu juga sebaliknya. Menurut Roskam et al., (2015) intervensi terkait parental self-efficacy lebih efektif untuk menstimulasi praktik pengasuhan yang positif.

Penelitian Kassabri et al., (2014) yang menyatakan bahwa rendahnya parental selfefficacy yang dimiliki oleh ibu berhubungan dengan pendisiplinan yang tidak konsisten dan menggunakan kekerasan, cenderung menyiksa anak, dan menjadi orang tua yang pasif. Rendahnya praktik pengasuhan positif dimensi pendisiplinan yang tepat dikarenakan masih banyak ibu yang tidak mengetahui cara mendisiplinkan anaknya secara tepat. Berdasarkan hasil wawancara yang dilakukan terdapat beberapa ibu menganggap bahwa memuji anak merupakan tindakan yang memanjakan anak. Ibu yang memuji anak, baik melakukan secara verbal dan hanya sebagian kecil yang memuji anak melalui kontak fisik seperti memeluk, menepuk pundak, mencium, memberi tepuk tangan, dan jempol. Sementara itu tingginya praktik pengasuhan negatif dimensi menunjukkan kemarahan dan pendisiplinan yang tidak konsisten dikarenakan ibu menganggap bahwa memarahi, mengomel, berteriak dan mengancam anak merupakan hal yang biasa dilakukan untuk menghentikan perilaku nakal anak. Rendahnya dan tingginya dimensi pendisiplinan yang tepat menunjukkan kemarahan dipengaruhi oleh pengalaman pengasuhan yang diterima oleh orang tua.

Berdasarkan teori psikoanalisis, perilaku seseorang dipengaruhi oleh keadaan jiwa dan pikiran seseorang yang merupakan hasil dari pengalaman masa lalunya (Hastuti, 2015). Hasil penelitian ini menunjukkan ibu bersikap hangat terhadap anak, namun karena kurangnya pengetahuan terkait pengasuhan yang positif membuat ibu menerapkan cara pendisiplinan yang tidak tepat. Hal ini menjadi tidak baik karena pengasuhan yang diterapkan orang tua akan memengaruhi tumbuh kembang anak. Idealnya orang tua harus menerapkan praktik pengasuhan yang mencintai dan hangat kepada anak, mengatakan hal baik tentang diri anak, bermain bersama anak, terlibat secara langsung dengan anak, menikmati kebersamaan dengan anak, memperlakukan anak seperti orang dewasa dan memuji anak di depan umum (Hastuti, 2015). Selain itu, orang tua juga harus menerapkan pendisiplinan yang tepat jika anak bersalah tidak menggunakan kekerasan serta mempermalukan anak di depan umum.

Hasil penelitian menunjukkan lebih dari separuh ibu memiliki parental self-efficacy di atas rata-rata, namun rata-rata penerapan praktik pengasuhan yang positif cukup rendah. Sementara itu, rata-rata penerapan praktik pengasuhan yang negatif cenderung tinggi. Hal ini dikarenakan parental self-efficacy bukanlah faktor tunggal yang memengaruhi praktik pengasuhan. Praktik pengasuhan dipengaruhi oleh faktor nature dan nurture. Menurut Baumrind faktor nature yang memengaruhi pengasuhan adalah kepribadian orang tua (Hastuti, 2015). Sementara itu, faktor nurture yang memengaruhi pengasuhan meliputi kualitas hubungan dengan pasangan, pengalaman pengasuhan yang dialami orang tua, dan pengetahuan terkait pengasuhan (Rubin \& Burgges, 2002; Grimes, 2012). 
Berdasarkan teori pembelajaran sosial Bandura, perilaku seseorang merupakan suatu bentuk respon dari stimulus yang diberikan. Sehingga praktik pengasuhan yang diterima oleh ibu pada masa kecil merupakan stimulus yang membentuk praktik pengasuhan yang diterapkan oleh ibu saat ini (respon). Pengetahuan ibu terkait pengasuhan juga dapat memengaruhi praktik pengasuhan yang diterapkan. lbu yang memiliki banyak pengetahuan terkait pengasuhan akan cenderung menerapkan praktik pengasuhan yang positif, dengan kata lain pengetahuan terkait pengasuhan memiliki peran penting dalam mengarahkan praktik pengasuhan yang diterapkan. Hal ini sejalan dengan Grimes (2012) yang menyatakan pengetahuan terkait pengasuhan memerankan peran penting dalam aplikasi parental self-efficacy pada praktik pengasuhan secara aktual.

Berdasarkan hasil penelitian diketahui bahwa lebih dari hampir dua pertiga anak memiliki tingkat perilaku agresif di bawah rata-rata. Hal ini berarti setiap anak pada penelitian ini melakukan tiga hingga empat perilaku agresif dari sepuluh perilaku agresif, dengan kata lain rata-rata anak pada penelitian cenderung memiliki perilaku yang agresif. Agresi merupakan perilaku yang dimaksudkan untuk melukai orang lain yang menghindar agar tidak terluka (Anderson \& Bushman, 2001). Menurut Papalia dan Olds (1986) agresivitas pada anak prasekolah dapat berlanjut jika anak dapat memperoleh keinginannya melalui perilaku agresif tersebut. Pada umumnya agresi yang dilakukan anak prasekolah bertujuan untuk mempertahankan mainan maupun wilayahnya.

Hasil regresi pada penelitian ini yang menunjukkan bahwa parental self-efficacy memiliki pengaruh yang berbanding terbalik dengan perilaku agresif anak, sedangkan praktik pengasuhan yang negatif memiliki pengaruh yang berbanding lurus dengan perilaku agresif anak usia prasekolah. Orang tua yang memiliki parental self-efficacy yang rendah cenderung menggunakan praktik pengasuhan yang negatif sehingga akan meningkatkan perilaku agresif anak sesuai dengan (Dumka et al., 2010, Garcia et al., 2012, Daganzo et al., 2014). Parental selfefficacy memengaruhi perilaku anak secara tidak langsung melalui praktik pengasuhan (Jones \& Prinz, 2005). Praktik pengasuhan negatif yang diterapkan oleh ibu dapat meningkatkan perilaku agresif pada anak prasekolah, hal ini dikarenakan anak prasekolah dipengaruhi oleh model yang berada di lingkungannya seperti orang tua. Hal ini sejalan dengan pernyataan Gunarsa (2014) yang menyatakan bahwa anak-anak dipengaruhi oleh model-model yang ada di dalam lingkungannya, seperti orang tua, guru, teman-teman dan juga televisi. Setiap perilaku tokoh atau model diamati baik yang positif maupun negatif (agresif) kemudian dijadikan suatu model tingkah laku untuk ditiru. Semakin sering model memperlihatkan suatu tingkah laku semakin besar pula kemungkinan anak akan meniru perilaku yang ditampilkan oleh model-model tersebut. Pada masa ini orang tua memiliki peran penting yaitu menjadi panutan bagi anaknya. Perilaku agresif anak dapat dihindari melalui praktik pengasuhan yang positif seperti memberikan reward (pujian, hadiah, tepuk tangan, dan lain-lain) jika anak berbuat baik dan memberikan hukuman yang tepat seperti (mengambil kesenangan, meminta anak memperbaiki kesalahan, dan tidak mengancam anak) ketika anak berbuat salah. Hal ini sesuai dengan teori Operant conditioning yang menyatakan bahwa seseorang akan mengulang suatu perilaku jika perilaku tersebut diberikan pengutan positif berupa reward dan suatu perilaku akan menghilang jika diberikan sanksi (Hastuti, 2015).

\section{SIMPULAN DAN SARAN}

Hasil penelitian menunjukkan rata-rata anak melakukan tiga hingga empat perilaku agresif dari sepuluh perilaku agresif. Perilaku agresif pada anak usia prasekolah dipengaruhi oleh parental self-efficacy dan praktik pengasuhan. Semakin rendahnya parental self-efficacy yang dimiliki oleh ibu maka praktik pengasuhan yang digunakan cenderung negatif sehingga akan meningkatkan perilaku agresif anak. Praktik pengasuhan positif yang diterapkan oleh ibu pada penelitian ini masih cukup rendah sedangkan praktik pengasuhan negatifnya cenderung tinggi, sehingga menunjukkan bahwa parental self-efficacy bukanlah merupakan faktor tunggal yang memengaruhi praktik pengasuhan. Namun, terdapat faktor lain seperti pengalaman pengasuhan yang diterima oleh ibu dan pengetahuan terkait pengasuhan yang tidak diteliti dalam penelitian ini. Hasil penelitian ini menemukan pengaruh antara parental selfefficacy dan praktik pengasuhan negatif terhadap perilaku agresif anak.

Berdasarkan hasil penelitian, dimensi kontrol serta disiplin dan penerapan aturan pada parental self-efficacy memiliki nilai rata-rata terendah. Peneliti menyarankan kepada orang tua untuk meningkatkan kedua dimensi 
tersebut, sehingga praktik pengasuhan dapat menjadi lebih baik. Cara yang dapat dilakukan oleh ibu untuk meningkatkan dimensi kontrol adalah dengan tetap bersikap tenang menghadapi masalah. Ibu juga harus tegas dan konsisten untuk menerapkan pendisiplinan jika anak bersalah, sehingga praktik pengasuhan negatif yang diterapkan dapat menurun. Ibu sebaiknya tidak menerapkan praktik pengasuhan yang negatif karena dapat meningkatkan perilaku agresif anak. Hasil penelitian juga menunjukkan bahwa dimensi pemarah pada perilaku agresif memiliki nilai rata-rata tertinggi. Sifat pemarah pada anak harus dapat dikendalikan sejak dini sehingga anak tidak menjadi individu yang impulsif dikemudian hari. Hasil penelitian ini dapat direkomendasikan kepada Kementerian Pendidikan dan Kebudayaan melalui Direktorat Pembinaan Pendidikan Keluarga sehingga dapat membuat program yang dapat meningkatkan parental self-efficacy ibu dan praktik pengasuhan yang positif. Salah satu jenis programnya dapat berupa konseling terkait praktik pengasuhan. Praktik pengasuhan positif yang belum optimal dapat ditingkatkan melalui bantuan penyuluhan dari LSM/ perguruan tinggi secara rutin dan menyeluruh. Penulis juga berharap kepada peneliti selanjutnya untuk meneliti juga parental self-efficacy dan praktik pengasuhan yang dimiliki olehayah sehingga parental selfefficacy dan praktik pengasuhan yang diterapkan dapat terlihat secara utuh.

\section{DAFTAR PUSTAKA}

[BPS] Badan Pusat Statistik. (2016). Kabupaten Bogor [internet]. Diambil dari https://bogorkab.bps.go.id/new/website/p df_publikasi/Kabupaten-Bogor-Dalam-

Angka-2016.pdf. [diunduh pada 4Mei 2017].

[KPAI] Komisi Perlindungan Anak Indonesia. 2015. KPAl: Pelaku Kekerasan pada Anak Tiap Tahun Meningkat [Internet]. [diunduh 2016 Desember 22]. Tersedia pada:http://www.kpai.go.id/berita/kpaipelaku-kekerasan-terhadap-anaktiaptahun-meningkat/.

Achenbach, T., \& Rescoria, L. (1991). Child behavior check list [Internet]. Diambil dari

http://www.aseba.org/preschool.html. [diunduh pada 21 Desember 2016].

Anderson, C. A., \& Bushman, B. J. (2001). Effects of violent video games on aggressive behavior, aggressive cognition, aggressive affect, physiological arousal, and physiological behavior: a meta-analytic review of the scientific literature. Psychological Science 12(5): 353-359. doi: 10.1111/1467-9280.00366.

Arriani, F. (2014). Perlaku agresif anak usia dini. Jurnal Pendidikan Usia Dini 2(8): 289-280. Diambil dari http://pps.unj.ac.id/journal/jpud/article/vie w/77. [diunduh pada 18 Januari 2017].

Azmoude, E., Jafarnejade, F.,\& Mazlom S. R. (2015). The predictors for maternal selfefficacy in early parenthood. Journal of Midwifery and Reproductive Health 3(2): 368-376. Diambil dari http://jmrh.mums.ac.ir/article_4050_548. html. [diunduh pada 1 Mei 2017]

Calvete, E., Orue, I. (2010). Cognitive schemas and aggressive behavior in adolescents: The mediating role of social information processing. Th Spanish Journal of Psychology. 13(1): 190-201.

Caplan, F. (1978). The Parenting Advisor. United State of America (USA): Anchor Press.

Coleman, P, K., \& Karraker, K, H. (2003). Maternal self-efficacy beliefs, competence in parenting, and toddlers' behavior and developmental status. Infant Mental Health Journal 4(2): 126148. doi: 10.1002/imhj.10048

Coleman, P. K., \& Karraker, K. H. (1998). Selfefficacy and parenting quality: Findings and future applications. Developmental Review, 18(1), 47-85. doi: 10.1006/drev.1997.0448

Coleman, P., \& Karraker, K. (2000) Parenting self-efficacy among mothers of schoolage children: conceptualisation, measurement and correlates. Family Relations 49, 13-24.

Daganzo, M. A. A., \& Alampay, L. P. (2014). Filipino Mothers' Self-Efficacy in Managing Anger and in Parenting, and Parental Rejection as Predictors of Child Delinquency. Philipp J Psychol 47(2): 1$26 . \quad$ Diambil dari https://www.ncbi.nlm.nih.gov/pmc/article s/PMC4662574/. [diunduh pada 18 Januari 2017].

Dewanggi, M., Hastuti, D., \& Hernawati, N.(2012). Pengasuhan orang tua dan kemandirian anak usia 3-5 tahun berdasarkan gender di Kampung Adat Urug. Jur. IIm. Kel. \& Kons 5(1): 19-28. 
doi: http://dx.doi.org/10.24156/jikk.2012. 5.1.19

Dowling, H. (2014). Parental self-efficacy in early years parenting. (Dissertation). University of Manchester

Duane, R., \& Grusec, E. J. (2006). Parenting Representation. United Kingdom (UK): Cambridge University Press.

Dumka, L. E., Gonzales, N. A., Wheeler, L. A., \& Millsap, R. E. (2010). Parenting selfefficacy and parenting practices over time in Mexican American families. Journal of Family Psychology, 24(5), 522-531. doi: 10.1037/a0020833

Dumka, L. E.,Gonzales, N. A., Wheeler, L, A., \& Milsap, R. E.(2010). Parenting selfefficacy and parenting practices over time in mexican american families. $J$ Fam Psychol 24(5): 522-531. doi:10.1037/a0020833.

Erlanti, M. S., Mulyana, N., \& Wibowo, H. (2016). Teknik parenting dan pengasuhan anak studi deskriptif penerapan teknik parenting di rumah parenting yayasan cahaya insan pratama bandung. Prosiding Ks: Riset \& $P k m$ 3(2): 155-291. Diambil dari http://jurnal.unpad.ac.id/prosiding/article/ view/13686/6524. [diunduh pada 18 Januari 2017].

Evans, J. L., \& Myers, R. G. (2000). Early childhood counts (a programming guide on early childhood care for development). Washington D.C., USA: The World Bank.

Fitriana, Y., Pratiwi, K., \& Sutanto, A. V. (2015). Faktor-faktor yang berhubungan dengan perilaku orang tua dalam melakukan kekerasan verbal terhadap anak usia prasekolah. Jurnal Psikologi Undip. 1(14):81-93.

Froman, R. D., \& Owen, S,V.(1990). Mothers and nurses perceptions of infant care skills. Research in Nursing \&Health.(13):247-253. doi 0160$6891 / 90 / 040247$.

Garcia, A. S., \& Alampay, L. P. (2012). Parental efficacy, experience of stressful life events, and child externalizing behavior as predictors of filipino mothers' and fathers' parental hostility and aggression. Philipp J Psychol 45(1): 124. Diambil dari https://www.ncbi.nlm.nih.gov/pmc/article s/PMC4184200/. [diunduh pada 18 Januari 2017]
Grimes, L. (2012). The role of parental selfefficacy and parental knowledge in parent-infant interactions during the transition to parenthood (Disertasi). Ohio: Bowling Green State University.

Gunarsa, S. D. (2014). Dasar dan teori perkembangan anak. Jakarta: Imprint BPK Gunung Mulia.

Hastuti, D. (2015). Pengasuhan: teori, prinsip, dan aplikasinya di Indonesia. Bogor, ID: IPB Press.

Hurlock, B. E. (1980). Psikologi Perkembangan. Istiwidayangti, Soedjarwo, penerjemah. Ridwan max Sijabat, editor. Terjemahan dari: Developmental Psycolgy A Life-Span Approach, Fifth Edition.

Imtaz, R., Yasin, G., Yaseen, A. (2010). Sociological study of factors affecting the aggressive behavior among youth. PJSS 30(1): 99-108.

Jones, D. J., Forehand, R., Rakow, A., Colletti, C. J., McKee, L., \& Zalot, A. (2008). The specificity of maternal parenting behavior and child adjustment difficulties: A study of inner-city African American families. Journal of Family Psychology, 22(2), 181-192. doi: 10.1037/08933200.22.2.181

Jones, T. L, \& Prinz, R. J. (2005). Potential roles of paretal self-efficacy in parent and child adjustment: A review. Clinical Psychology Review 25: 341-363. doi: 10.1016/j.cpr.2004.12.004.

Kassabri, M. K., Schwartz, S. A., \& Zur, H. (2014). Understanding the mediating role of corporal punishment in the associatin between maternal stress, efficacy, coparenting and children's adjustment difficulties among Arab mothers. Child Abbuse \& Neglect.1-10. Diambil dari http://dx.doi.org/10.1016/j.chiabu.2014.0 4.009. [diunduh pada 6 Juni 2017].

Koeske, G. F., \& Koeske, R. D. (1990). The buffering effect of social support on parental stress. J. Orthopsychiat 60(3): 440-451. doi: 10.1037/h0079164.

Leahy-Warren, P., McCarthy, G., Corcoran, P. (2011). First-time mothers: social support, maternal parental self-efficacy and postnatal depression. Journal of Clinical Nursing, 21, 388-397 doi: 10.1111/j.1365-2702.2011.03701.x

Nelson, D. A., Hart, C. H., Yang, C., Olse, J. A., \& Jin, S. (2006). Aversive parenting 
in china: associations with child physicaland relational aggression. Child Development 77 (3): 554 - 572. doi: 10.1111/j.1467-8624.2006.00890.x.

Page, M., Wilhelm, M. S., Gamble, W. C., \& Card, N. A. (2010). A comparison of maternal sensitivity and verbal stimulation as unique predictors of infant social-emotional and cognitive development. Infant Behavior and Development, 33(1),101-110. doi: 10.1177/107484079800400206

Papalia, D. E., \& Olds, S. W.(1986). Human Development.United State of America (USA): McGraw-Hill, Inc.

Papalia, D. E., Olds, S. W., Feldman, R. D. (2009). Perkembangan Manusia Ed ke10.Marswendsdy B. penerjemah; Widyaningrum. editor. Jakarta (ID): Penerbit Salemba Humanika. Terjemahan dari Human Development ed 10th.

Reebye, P. (2005). Aggression during early years infancy and preschool. The Canadian Child and Adolescent Psychiatry Review 14(1): 16-20. Diambil dari

https://www.ncbi.nlm.nih.gov/pmc/article s/PMC2538723/. [diunduh pada 18 Januari 2017]

Roskam, I., Brassart, E., Loop, L., Mouton, B., \& Schelstraete, M. A. (2015). Stimulating parents' self-efficacy beliefs or verbal responsiveness: Which is the best way to decrease children's externalizing behaviors?.Behaviour Research and Therapy. 72: 38-48. doi: 10.1016/j.brat.2015.06.012.

Rubin, H. K., \& Burgess, K. B. (2002). Parents of Aggressive and Withdrawn Children. Bronstein $\mathrm{MH}$, editor. New Jersey: Lawrence Erlbaum Associates.

Rudy, D., \& Grusec, J. E. (2006). Parenting Representation : Sub Bab Social Cognitive Approaches to Parenting
Representations. Ofra M, editor. (USA):Cambridge University Press.

Salonen, A. H., Kaunonen, M., Astedt-Kurki, P., Jarvenpaa, A. L., Isoaho, H., \& Tarkka, M., T. (2010). Parenting selfefficacy after childbirth. Journal of Advanced Nursing. 65(11):2324-2336. doi: 10.1111/j.1365-2648.2009.05113.x.

Sanders, M. R., \& Woolley, M. L. (2005). The relationship between maternal selfefficacy and parenting practices: implications for parent training. Child: Care, Health \& Development, 31(1), 65$73 . \quad$ doi: $10.1111 / \mathrm{j} .1365-$ 2214.2005.00487.x

Santrock, J. W. (2011). Perkembangan Masa Hidup. Benedictine Widyasinta, penerjemah. Jakarta, ID: Erlangga. Terjemahan dari: Life-span Development.

Simons, R. L., Whitbeck, L. B., Conger, R. D., Melby, J. N. (1990). Husband and Wife Differences in Determinants of Parenting: A Social Learning and Exchange Model of Parental Behavior. Journal of Marriage and Family 52 (2): 375-392. doi: 10.2307/353033.

Stromshak, E. A., Bierman, K. L., McMahon, R.J., \& Lengua, L. J. (2000). Parenting Practices and Child Disruptive Behavior Problems in Early Elementary School.J Clin Child Psychol. 29(1): 17-29.doi: 10.1207/S15374424jccp2901_3.

Weaver, C. M., Shaw, D. S., Dishion, T. J., \& Wilson, M. N. (2003). Parenting selfefficacy and problem behavior in children at high risk for early conduct problems: the mediating role of maternal depression. Infant Behavior and Development: 11.doi: 10.1016/j.infbeh.2008.07.006.

Young, S. L. (2011).Exploring the relationship between parental selfefficacy and social support systems (thesis). Lowa: Lowa State 